\title{
Detection, identification and characterization of extended-spectrum beta- lactamases producing Enterobacteriaceae in wastewater and salads marketed in Ouagadougou, Burkina Faso
}

\author{
Souleymane SORÉ ${ }^{1,2^{*}}$, Yacouba SAWADOGO ${ }^{5}$, Juste Isidore BONKOUNGOU ${ }^{3}$, \\ Sephora P. KABORÉ 2 , Saidou BÉOGO ${ }^{4}$, Charles SAWADOGO ${ }^{1}$, Boubié G. BATIONO ${ }^{1}$, \\ Hervé KY ${ }^{1}$, Patrick Djim-Madjim MADINGAR ${ }^{1}$, Abdoul Salam OUÉDRAOGO ${ }^{5}$ and \\ Idrissa SANOU ${ }^{2,4}$ \\ ${ }^{1}$ Direction of medical biology labs, Health Ministry, 03 Po box 7022 Ouagadougou 03, Burkina faso. \\ ${ }^{2}$ Saint Thomas d'Aquin University, Doctoral School of Sciences, Health and Technologies, 06 Po box 10212 \\ ouagadougou 06, Burkina Faso. \\ ${ }^{3}$ Laboratory of Applied and Nutritional Sciences (LabSAN), University Prof. Joseph KI-ZERBO, 03 Po \\ box7021, Ouagadougou 03, Burkina Faso. \\ ${ }^{4}$ Tengandogo Teaching Hospital, 11Po box 104 ouagadougou CMS 11, Burkina Faso. \\ ${ }^{5}$ Souro Sanou University Hospital, Bobo-Dioulasso, Burkina Faso. \\ *Corresponding author ; E-mail: soulsore11@yahoo.fr ; Tel.: (00 226) 72042915
}

\begin{abstract}
Extended spectrum beta-lactamase producing Enterobacteriaceae (ESBL-PE) represent a threat for failure of empirical antibiotic therapy and are associated with high mortality, morbidity and expenses. The aims of this study was to determine the prevalence of ESBL-PE and multidrug resistant enterobacteria (MDR), enterobacteria profil, investigate the associated resistance in wastewater and salads. After wastewater and salad sampling, enterobacteria was isoled on $(\mathrm{EMB}+4 \mu \mathrm{g} / \mathrm{L}$ cefotaxim). The stains of Enterobacteriaceae were identified by using biochemical methods and confirmed as ESBL by double-disc synergy test (amoxicillin/clavulanic acid with cefotaxime $30 \mu \mathrm{g}$, ceftazidime $30 \mu \mathrm{g}$ and ceftriaxone $30 \mu \mathrm{g}$ ). Finally, the associated resistance was investigated by testing the susceptibility of the strains by the disc diffusion method. Global prevalence of ESBL-PE was 53.92\% (95\% CI: 48,2-59,5) (153/293), 61.11\% from wastewater and $42.47 \%$ from salads. Major ESBL-E was Escherichia coli $(73.44 \%)$, followed by Klebsiella pneumoniae $(21.88 \%)$. Resistance to the aminoglycoside , fluroquinolonones and sulfonamides classes were dominant, observed in $53,83 \%, 93,86 \%$ and $98,95 \%$ of the isolates, respectively. The frequence of MDR was hight to channel $_{1}(32,40 \%)$ and channel $2(26,26 \%)$. This study reports very worrying results. There is an urgent need to develop measures to monitor the spread of these multidrug-resistant strains.
\end{abstract}

(C) 2020 International Formulae Group. All rights reserved.

Keywords: Wastewater, ESBL-PE, Salads, Ouagadougou.

\section{INTRODUCTION}

The discovery of antibiotics have been a major breakthrough in the human history.
However, antibiotic resistance is an urgent and growing global health concern. By 2050, predictions estimate that over 10 million of 
deaths and $\approx 100$ trillion USD total cost derived from antibiotic resistance worldwide (Maestrecarballa et al., 2019). Globally, significant amounts of antibiotics used in domestic treatments, hospitals and cattle farming end up, directly or indirectly, in wastewater (Svobodova et al., 2018). This creates resistance in the environmental microbiota. In addition to this human, animal stool passes through sewage channels through runoff. All these show that wastewater is thus considered to be hotspots for dissemination of antibacterial resistance into the environment (Rousham et al., 2018). Multidrug-resistant bacteria have been detected from various wastewater resources, which is an underappreciated exposure route for the dissemination of resistant bacteria. This wastewater is sometimes used to water salad, lettuce, tomatoe (Ouedraogo et al., 2018). In SubSaharan Africa, 50 to $90 \%$ of the vegetables consumed by city dwellers are produced in urban or peri-urban areas mainly with wastewater (Drechsel et al., 2006). In addition, the demographic growth of the city generates an increase in food needs, especially market garden products. However, due to the lack of irrigation water in urban and peri-urban areas, farmers resort to wastewater, which is often untreated or poorly treated, which is a potential source of multidrug-resistant bacteria from households, hospitals and farms (Sou, 2009). The city of Ouagadougou is largely supplied with market gardening products using water from dams, wells and boreholes, but above all wastewater, the quality of which remains questionable. Among multidrug-resistant bacteria (MDRB), Extended-spectrum $\beta$ lactamase (ESBL)-producing Enterobacteriaceae have increased in occurrence globally in health care systems, agro-ecosystems, and fresh produce, due to the widespread use of broad spectrum antibiotics (Ye et al., 2017). Recently, the World Health Organization (WHO) listed the extendedspectrum $\beta$-lactamase-producing Enterobacteriacae (ESBL-PE) as a priority pathogen for the research and development of newer drugs (WHO, 2014). The acquisition and expression of the ESBL resistance genes lead to the ability of Enterobacteriacae to hydrolyze and resist several types of $\beta$-lactam antibiotics, including the third-generation cephalosporins, monobactams except cephamycins and carbapenems (Gundran et al., 2020). Infections caused by multidrug resistant bacteria are associated with higher mortality, morbidity and healthcare costs (Ndir et al., 2016). Enterobacteriacae producing extendedspectrum- $\beta$-lactamases (ESBLs) represent main challenges to antibiotic therapy, with increasing prevalence rates throughout the world (Doi et al., 2017). In Burkina Faso, the number of clinical infections with ESBLproducing organisms is increasingly high (Ouedraogo et al., 2016). Precise information about the spreading of ESBL-organisms influenced by wastewater systems and food is poorly known. However contamination of multidrug-resistant Enterobacteriaceae onto fresh produce occurs through the use of contaminated irrigation water or human fecal contamination (Blaak et al., 2014) Subsequent transfer to humans can happen through consumption of raw vegetables, potentially impacting consumer health negatively (Ye et al., 2017). Current knowledge concerning the presence of ESBL-producing enterobacteria on fresh vegetables in Burkina Faso is limited because there are few study has been carried out. The aim of this study was to detect, identify, and characterize ESBL-producing Enterobacteriaceae isolates from wastewater and marketed salads frequently consumed in Ouagadougou.

\section{MATERIALS AND METHODS}

\section{Wastewaster and salad leaves collection}

Wastewater samples (180) (each with the volume of $500 \mathrm{~mL}$ ) were collected into sterile bottles, transported to the laboratory at a temperature of $4{ }^{\circ} \mathrm{C}$. In addition to wastewater a total of 113 salads samples were collected from 9 sellers from two vegetable markets from January 2020 to June 2020. In this informal markets, street traders display salad, fresh produce on a table, underneath a shade covering, at the roadside, or they use mobile trolleys. All samples were transported in cooler boxes and stored at $4{ }^{\circ} \mathrm{C}$. 


\section{Type, period of study and sample processing}

This was a prospective cross-sectional study from January 2020 to June 2020. Three sewage channels and two salad markets were used for sampling. It was:

- Wastewater from channel ${ }_{1}$, located behind Yalgado Ouedraogo University Hospital (CHU-YO), which take waste coming from nursing and domestic;

- Wastewater from Paspanga (Ouagadougou city quarter) channel named channel $_{2}$ situaded on middel of domestic build, which receives waste coming from domestic, commercial and industrial.

- Wastewater from the third channel named channel $_{3}$, located in front of remand and correctional house of Ouagadougou, which receives wastewater from the surrounding residents, commercial buildings, domestic were chosen for sampling.

- Wayalghin and Tanghin vegetable market where a total number of 113 feet of salads were collected from 9 sellers chosen at random (Figure 1).

- After homogenizing the wastewater bottles, $10 \mathrm{ml}$ was used to centrifuge $2500 \mathrm{rpm}$ for 5 min.

- Each head of salad sample was aseptically cut into a sterile bag containing $20 \mathrm{~mL}$ distilled water, $10 \mathrm{ml}$ of this was blended in $2500 \mathrm{rpm}$ for $5 \mathrm{mn}$.

\section{Isolation and identification of enterobacteriaceae}

On January to June 2020 a total of 101 wastewater in direct contact of human and animal to the water were screened. $10 \mathrm{~mL}$ of wastewater was centrifuge and seeded brothheart-brain (HiMedia, india) and incubated for overnight at $37^{\circ} \mathrm{C}$ to improve the bacteriological yield (Lauderdale et al., 2010). After this enrichment, $10 \mu \mathrm{l}$ of the broth was transferred to Eosine methylen bleu (EMB) agar (HiMedia, india) supplemented with $4 \mu \mathrm{g}$ / $\mathrm{L}$ of cefotaxim and incubated at $37^{\circ} \mathrm{C}$ for 24 hours. Predominant colonies of different morphotypes were identified to species level by using phenotypic characteristics, Gram staining, oxidase, and fermentation tests.
Bacteria Gram-negative, oxidase negative and fermentation-positive isolates were biochemically identified by using in-house biochemical tests (Triple Sugar Iron Agar, Sulfur-Indole-Motility test, Simmons's citrate agar, and urease test).

\section{Phenotypic ESBL/AmpC testing}

All enterobacterial isolates were screened for ESBL production by the doubledisk synergy test (DDST) using cefotaxime 30 $\mu \mathrm{g}$, ceftazidime $30 \mu \mathrm{g}$, ceftriaxone $30 \mu \mathrm{g}$ and amoxicillin/clavulanic (20/10 $\mu \mathrm{g})$. Phenotypic detection of AmpC production was carried out for enterobacteriacae strains that were either resistant to cefoxitin and/or resistant to $\geq 3 \beta$ lactam antibiotics (CA-SFM, 2013).

\section{Antimicrobial susceptibility testing}

Presumptive ESBL-producing

Enterobacteriaceae isolates were analysed by Kirby-Bauer disk diffusion technique to determine the resistance patterns of the isolates(CA-SFM, 2013). The strains were tested for susceptibility to antimicrobial susceptibility using the cefotaxime (CTX 30 $\mu \mathrm{g}$ ), ceftazidime (CAZ $30 \mu \mathrm{g}$ ), ceftriaxone (CRO $30 \mu \mathrm{g}$ ), cefoxitine (FOX $30 \mu \mathrm{g}$ ), amoxicillin/clavulanic (AMC $(20 / 10 \mu \mathrm{g})$, imipinem (IPM $10 \mu \mathrm{g}$ ), gentamicin (CN $10 \mu \mathrm{g}$ ), ciprofloxacin (CIP,5 $\mu \mathrm{g})$, trimethoprim/sulfamethoxazole

(SXT,1.25/23.75 $\mu \mathrm{g})$, (Oxoid Ltd., Basingstoke,UK). Zones of inhibition were measured with a precision caliper. Isolates exhibiting resistance to at least three antimicrobial agents tested were considered as multidrug-resistant strains (CA-SFM, 2013). Zone diameters were compared with the EUCAST criteria to determine if isolates were resistant, intermediate, or susceptible.

\section{Quality control}

Standard operating procedures have been strictly followed. The expiration dates of culture media, reagents and other consumables have been checked and documented. A verification of the contaminants of the media already prepared was carried out by sterility test. A quality control was carried out in order 
to test fertility of media. Each new batch was checked before use by testing Escherichia coli ATCC 25922 which is one of the standard control strains. During the detection of ESBLPE, Klebsiella pneumoniae ATCC 700603 (ESBL-PE positive) and Escherichia coli ATCC 25922 were used as controls for this study.

\section{Statistical analysis}

Data entry was performed on Excel 2013 and statistical analysis of the results using XLSTAT 2020 version 3.1. The figures were produced using Excel 2013. A p-value $<0.05$ was considered significant. Chi-square test was used to analyze variables.

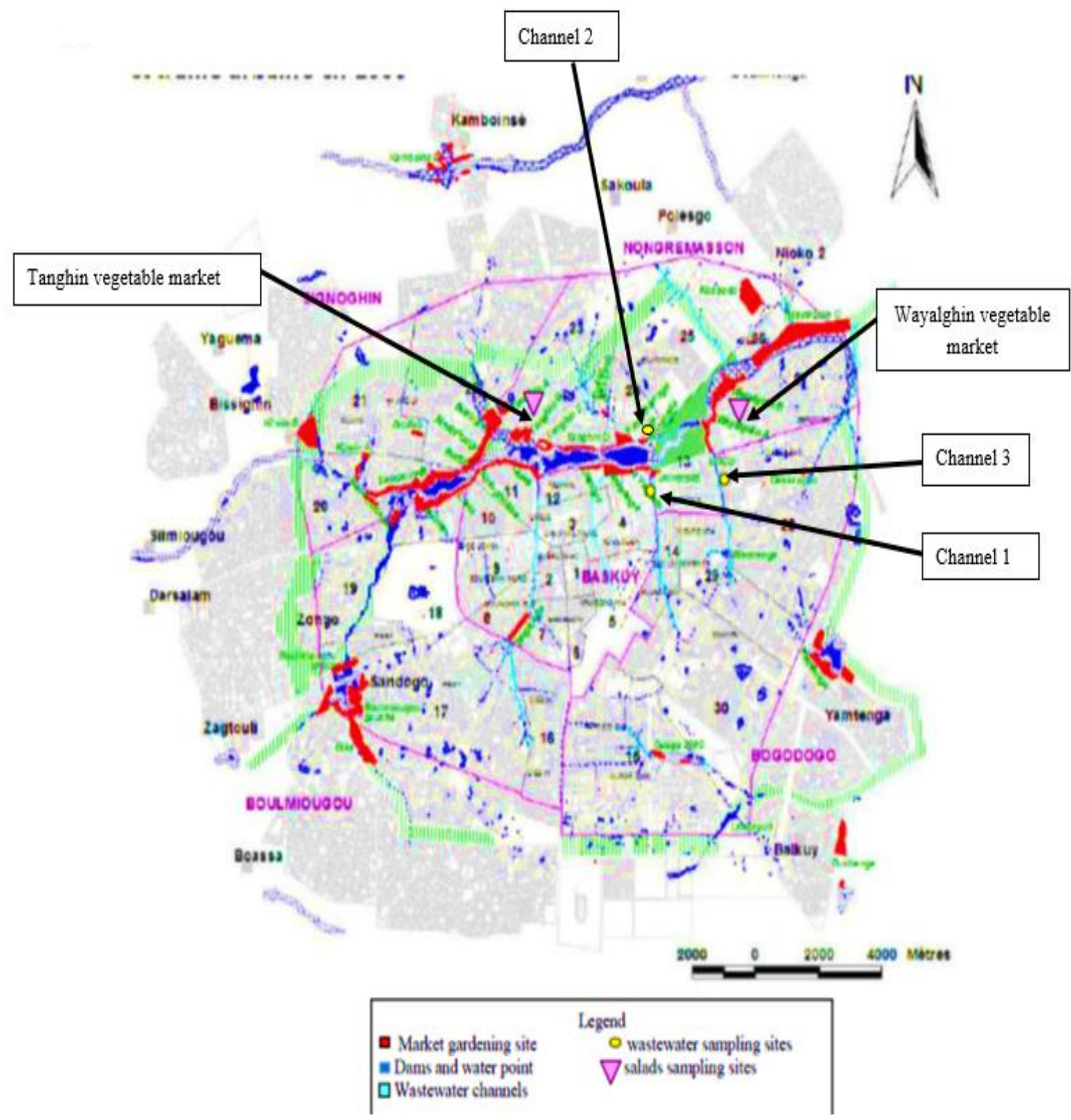

Figure 1 : Wastewater and fresh salads sampling sites.

(Kêdowidé et al., 2010). 


\section{RESULTS}

Prevalence of ESBL-PE in wastewater and marketed salad

The 293 samples analysed originated mostly from wastewater channels $(\mathrm{n}=180)$ and salads leaves $(n=113)$. ESBL-PE isolates were detected in 158 out of 293 wastewater and salads sample analyzed $(53.92 \%)(95 \% \mathrm{CI}=$ 48.2-59.5). Prevalence obtained from wastewaster used for irrigation was $61.11 \%$ (110 of 180 ) and from salads heads sampled was $42.47 \%$ (48 of 113) (Table 1). There is significant difference in the prevalence rate between wastewater samples and salads samples $(p=0.002)$. In the origin of water sample the prevalence was the highest in channel $_{3}$ and channel $l_{1}, 93.33 \%$ and $56.67 \%$ $(p<0.0001)$ respectively (Table1).

\section{Prevalence of presumptive ESBL-AMPc- producing Enterobacteriaceae}

A total of 293 from three wastewater and salads samples were further analysed. Combined ESBL- and AmpC-producing phenotypes were observed in 19 of 293 (6.48\%)(95\% CI : 4.2-9.9) of the isolates. Prevalence of phenotype ESBLs +AmpC was highest in channel 2 (13.3\%), followed by channel $_{1}$ water $(11.11 \%)$ and salad $(1.56 \%)$ (Figure 2).

\section{Bacteriological profile of ESBL-PE}

ESBL-PE isolates were identified as Escherichia coli $(73.44 \%)$, Klebsiella pneumoniae (21.88\%) Klebsiella oxytoca, Serratia spp and Citrobacter spp (Table 2).

\section{Susceptibility of ESBL-PE to antibiotics isolates in wastewater and marketed salad in Ouagadougou}

The antibiogram of ESBL-PE isolates is given in Figure 3. All isolates were sensitive to carbapenems . A high resistance rate was observed in ciprofoxacin $(93.75 \%$ in wastewater and $65.50 \%$ for salads leaves), gentamicin $(45.83 \%$ in wastewater and $79.17 \%$ in salads leaves), sulfamethoxazole trimethoprime $(98.61 \%$ in wastewater and $100 \%$ salads leaves) and amoxicillin/clavulanic acid $(85.42 \%$ in wastewater and $91.67 \%$ salads leaves). Absolute resistance was observed in cefotaxime $(100 \%)$, ceftriaxone $(100 \%)$ and ceftazidime $(100 \%)$

\section{Distribution of multi-drugs resistantance Enterobacteria and associated resistance}

ESBL-producing Enterobacteriaceae resistant to more than three antimicrobial classes, was $179 / 192(93.23 \%)(95 \%$ CI $=$ 88.8-96.0). Resistance to the aminoglycoside , fluroquinolonones and sulfonamide classes were dominant, observed in $53.83 \%, 93.86 \%$ and $98.95 \%$ of the isolates, respectively. Among site of sampling, frequence of MDR were hight to channel ${ }_{1}(32.40 \%)$ and channel $_{3}$ (26.26\%) (Figure 4).

Table 1 : The frequence of ESBL producing Enterobacteriaceae isolated from wastewater and salads leaves according to site of sampling.

\begin{tabular}{llllll}
\hline Origin & location & No of Positive & Prevalence (\%) & No of Sample & 95\% CI \\
\hline Wastewater & Channel $_{1}$ & 51 & 56,67 & 90 & $46,4-66.4$ \\
& Channel $_{2}$ & 31 & 51,67 & 60 & $39,3-63,8$ \\
& Channel $_{3}$ & 28 & 93,33 & 30 & $78,6-98,2$ \\
\multirow{3}{*}{ Salads leaves } & W Market & 25 & 39,06 & 64 & $28,0-51,3$ \\
& T Market & 23 & 46,94 & 49 & $33,7-60,6$ \\
& Total & 158 & 53,92 & 293 & $48,2-59,5$ \\
\hline
\end{tabular}

No: number, W market: walyalguin vegetable market, T market: Tanghin vegetable market; CI :confidence interval. 


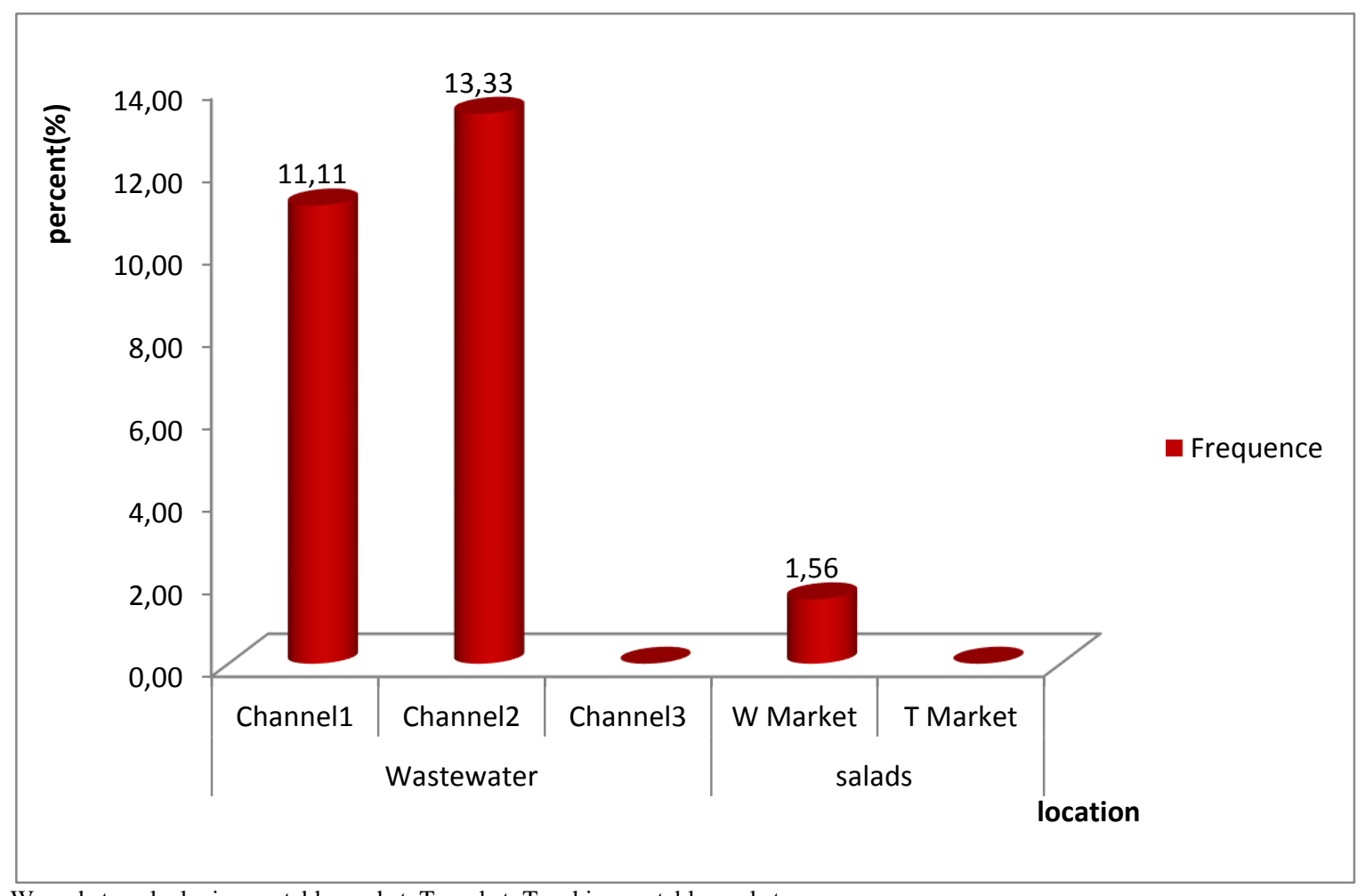

$\mathrm{W}$ market: walyalguin vegetable market, T market: Tanghin vegetable market.

Figure 2: The frequency of presumptive conjugative ESBL/AmpC isolates from wasterwater and salads leaves in Ouagadougou.

Table 2 : Percentage of isolated ESBL-PE strains from wastewater and salads leaves in Ouagadougou.

\begin{tabular}{lllllll}
\hline ESBL-PE & \multicolumn{2}{l}{ Wastewater } & \multicolumn{2}{l}{ Salads leaves } & Total & \\
\cline { 2 - 7 } & $\mathbf{n}$ & $\%$ & $\mathbf{n}$ & $\%$ & $\mathbf{n}$ & $\%$ \\
\hline Escherichia coli & 135 & 93,75 & 6 & 12,50 & 141 & 73,44 \\
Klebsiella pneumoniae & 7 & 4,86 & 35 & 72,92 & 42 & 21,88 \\
Klebsiella oxytoca & 1 & 0,69 & 0 & 0,00 & 1 & 0,52 \\
Serratia spp & 1 & 0,69 & 0 & 0,00 & 1 & 0,52 \\
Citrobacter spp & 0 & 0,00 & 7 & 14,58 & 7 & 3,65 \\
Total & 144 & 100,00 & 48 & 100,00 & 192 & 100,00 \\
\hline
\end{tabular}




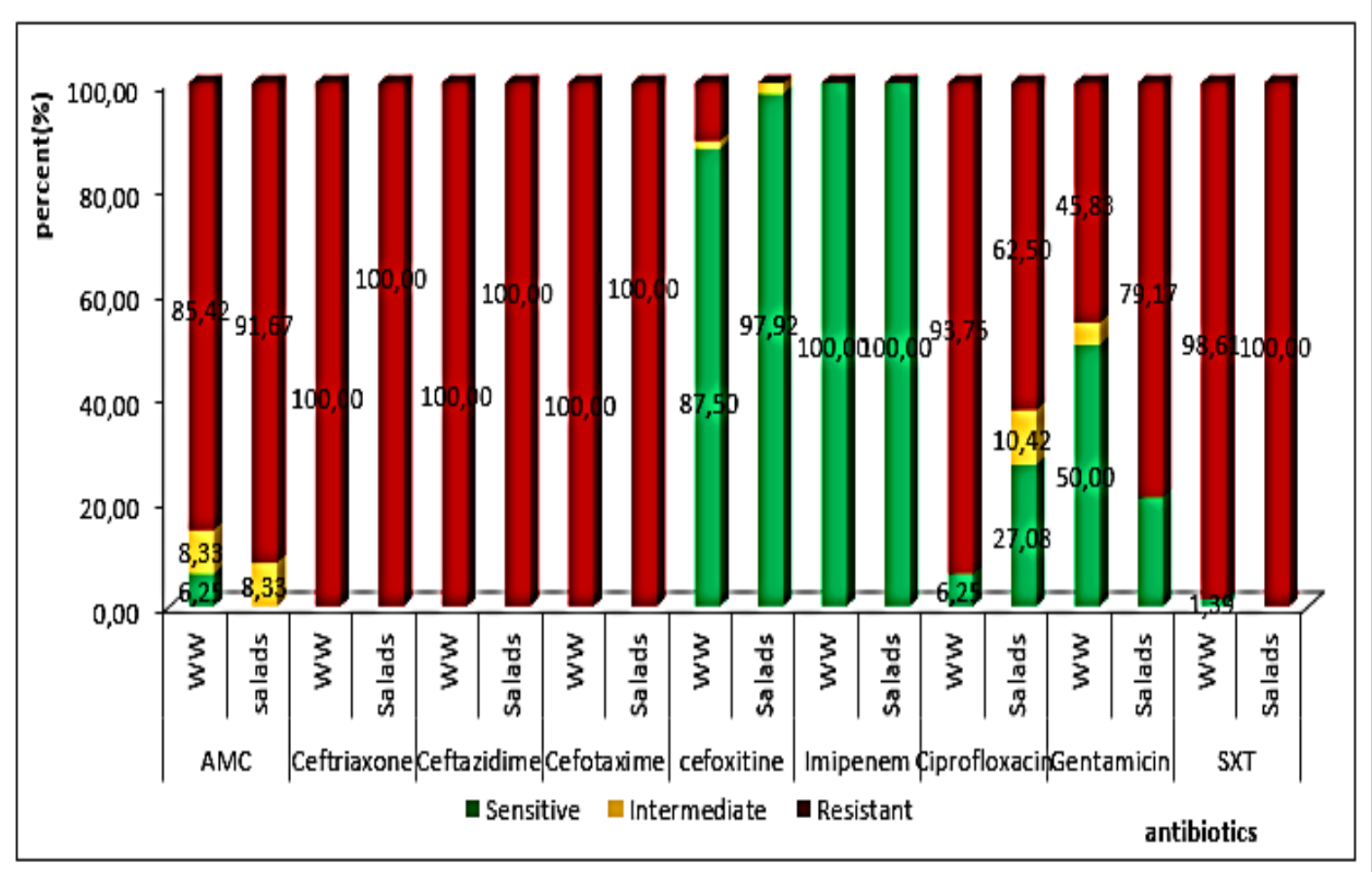

AMC: amoxicillin/clavulanic; SXT: trimethoprim/sulfamethoxazole; WW: wastewater.

Figure 3: Antimicrobial resistance pattern of extended-spectrum $\beta$-lactamase-producing enterobacteriacae isolates from wastewater and salads.

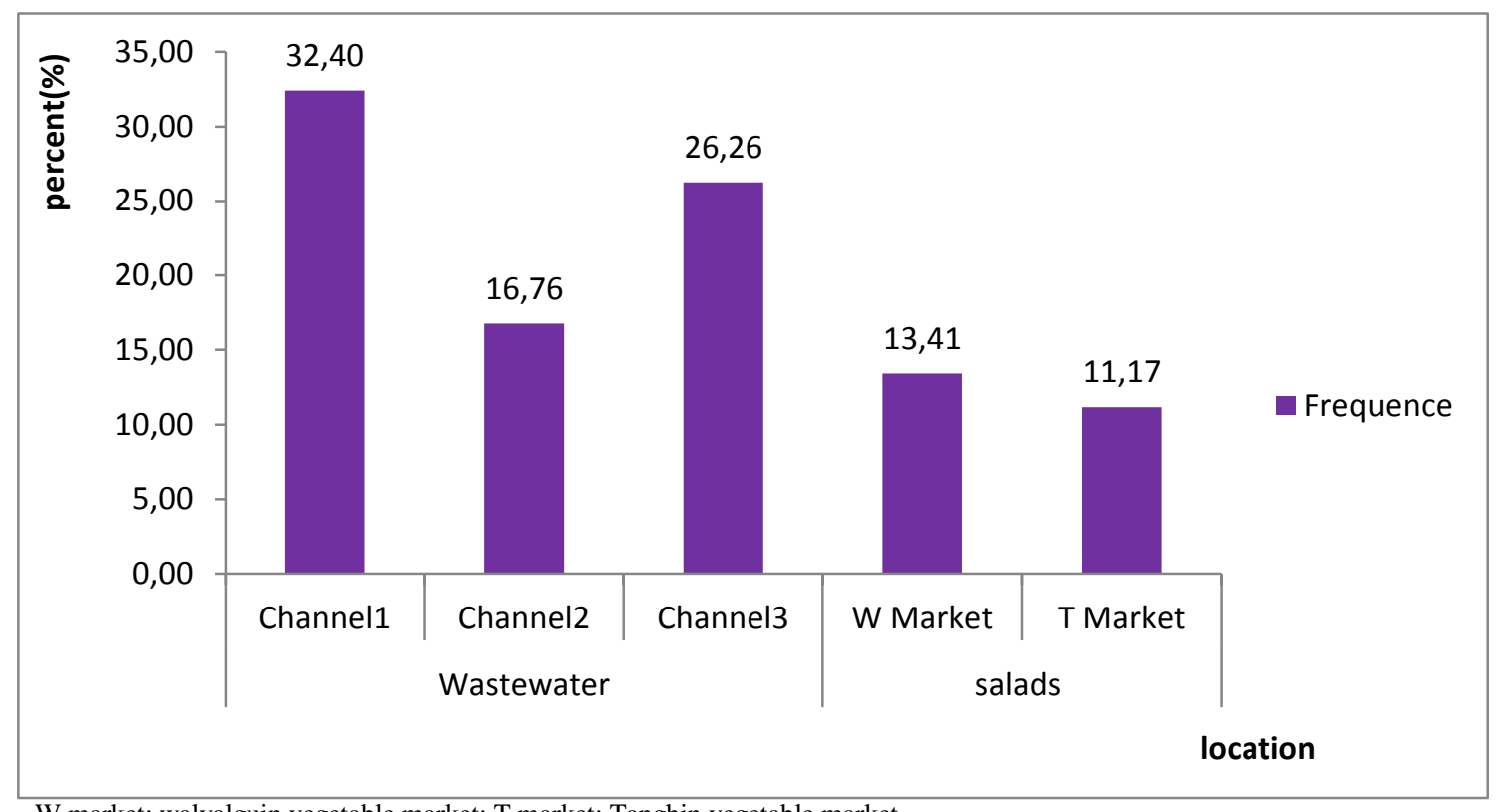

W market: walyalguin vegetable market; T market: Tanghin vegetable market.

Figure 4 : Repatition of MDR isolates from wastewater and salads leaves in Ouagadougou. 


\section{DISCUSSION}

\section{Prevalence of ESBL-PE in wastewater and marketed salad}

High global prevalence $(53.92 \%)$ of ESBL-PE was seen in isolates from wastewater and salads. This high frequency could be explained by the fact that in Burkina Faso, the use of antibiotics is excessive and not controlled in human and animal health (Samandoulougou et al., 2015). In addition, the remains of the antibiotics used and the faeces are poured into the hospital and domestic evacuation channels (Akiba et al., 2015; Lan et al., 2019) . Their presence in the environment could lead to the emergence of antibioticresistant bacteria. Even if antibiotics consumption were reduced, the existing concentrations of antibiotics and the resulting selective pressure on bacterial communities could persist in the environment for long periods of time (Osinka et al., 2016). Other authors have shown that there is a high concentration of antibiotics in the environment and the presence of ESBL-PE in the environment including wastewater and salads (Sallem et al., 2012; Thevenon et al., 2012). However in the city of Ouagadougou, capital of Burkina Faso, the practice of horticulture is booming. It is conducted around any accessible water point, both inside and on the outskirts of the city. The investigations showed that $75 \%$ of the farmers use wastewater for their activities (Ouedraogo et al., 2018). Therefore, this high prevalence of ESBL-PE detected in salads could increase human fecal carriage if the microbial flora of the salads is not well inactivated by washing with sodium hypochlorite. Analysis of the antibiotic susceptibility revealed that a high percentage $(93.23 \%)$ of the multidrug-resistance phenotype isolated from wastewater and salad, and the prevalence was higher than that previously reported in south china (Tao et al., 2010) and was even higher than the common antibiotic resistance profiles of Enterobacteriaceae in aquatic environments (Maravić et al., 2015). This frequency of multiresistant enterobacteria isolated in the environment could be concealed in humans and animals by the consumption of water and contaminated food.

\section{Bacteriological profile of ESBL-PE}

Among the ESBL-PE, the most isolated were Escherichia coli and Klebsiella pneumoniae both in wastewater and in salads, with frequencies of $73.44 \%$ and $21.88 \%$ respectively. Escherichia coli have been implicated in foodborne disease out-breaks, while Klebsiella pneumoniae, Serratia spp, Citrobacter spp, and Enterobacter spp. are regarded as opportunistic human pathogenic bacteria (Baylis et al., 2011). Subsequent transfer to humans can happen through consumption of raw vegetables, potentially impacting consumer health negatively (Ye et al., 2017). Indeed Escherichia coli represents $80 \%$ of urinary tract infections and are also implicated in suppurative infections. As for Klebsiella pneumoniae, it is implicated in respiratory and postoperative infections. This high proportion of these two species among ESBL-PE is the cause of treatment failure for the infections that they may bring about. Most studies carring on ESBL-PE isolate in environnement have shown a predominance of Escherichia coli which may host a gene located on a plasmid which codes for the production of ESBLs, which would facilitate the transfer to other bacteria, which justifies a multitude of enterobacteria (Escherichia coli, Klebsiella pneumoniae, Klebsiella oxytoca, Citrobacter spp) among ESBL-PE. This predominance of the species Escherichia coli and Klebsilla pneumoniae in wastewater is linked to the fact that these two E-ESBLs are also the most isolated in digestive carriage in humans and animals (Ouédraogo et al., 2017; Sanou et al., 2019). In addition, these enterobacteria are the most isolated in infectious pathology in three hospitals in Burkina faso (Kpoda et al., 2017).

\section{Susceptibility rate of ESBL-PE to antibiotics in wastewater and marketed salad in Ouagadougou}

The ESBL-PE showed any resistance to imipenem. These enterobacteria were also showed resistance to ciprofoxacin $(93.75 \%$ in wastewater and $65.50 \%$ for salads leaves), 
gentamicin (45.83\% in wastewater and $79.17 \%$ in salads leaves) and sulfamethoxazole trimethoprime $(98.61 \%$ in wastewater and $100 \%$ salads leaves). This high resistance to fluoroquinolones, aminoglycosids and sulfamethoxazole - trimethoprime is probably due to their easy access, their increased use and non-control of these antibiotics on the market. Fluoroquinolone-resistant ESBL-PE is a concern in human medicine because this family of antibiotics are commonly used for treatment of urinary tract infections (Gundran et al., 2020). Apparently, gentamicin is the most common antibiotic under the aminoglycoside family used in our country. In addition to this, the plasmids carrying genes encoding ESBLs also carry other genes conferring resistance to fluoroquinolones, aminoglycosides, cotrimoxazole (Ouédraogo et al., 2017).

\section{Distribution of multi-drugs resistantance Enterobacteria and associated resistance}

Of the 192 ESBL-PE isolates, 179 isolates (93.23\%) showed multidrug resistance, that is resistance to at least three antimicrobials (Figure 3). This high prevalence of MDR Enterobacteriacae, was $94.40 \%$ in wastewater and $91.66 \%$ salads. The highest MDR was observed for E. coli, Klebsiella spp, Citrobacter spp isolates obtained from water and salads. These strains showed resistance to antimicrobial classes of $\beta$-lactams, aminoglycosids, fluoroquinolone, and sulfonamide. The fact that salads can serve as a reservoir of MDR ESBL/AmpC-producing Enterobacteriaceae. It constitutes a potential health risk to the consumer, because this is used to treat human infections (Richter et al., 2019). Antimicrobial resistant Enterobacteriacae contaminants in salads or vegetable can be a factor of risk for the spread of community acquired antimicrobial resistance via the consumption of fresh produce. This is similar to reports from similar studies that showed prevalence of MDR $(96.1 \%)$ and resistance to aminoglycosides (46.7-66.7 ) in ESBLproducing Enterobacteriaceae ( Zurfluh et al., 2015; Richter et al., 2019).

\section{Conclusion}

We report the results of the first investigation of the detection, identification and characterization of ESBL- producing Enterobacteriaceae isolated from wastewater and salads leaves in Ouagadougou. This work showed that wastewater and salads are important vehicles for the dissemination of ESBL producing enterobacteria. Therefore, close surveillance of antimicrobial resistance in bacteria from waste and food-producing should be established as a priority. In addition, strategies to control living of hospital and domestic waste in channel must be develop to trait wastewater before using to water salads, vegetable and lettuce.

\section{COMPETING INTERESTS}

The authors declare that they have no competing interests.

\section{AUTHORS' CONTRIBUTIONS}

SS contributed to designed the work that led to the submission, acquired data, and played an important role in interpreting the results. SS , A O and IS contributed to revised the manuscript and approved the final version. SPK, SB and YS helped to acquired data. JIB, SS, BGB, HK, P D-MM, ASO and IS helped perform the analysis with constructive discussion.

\section{ACKNOWLEGEMENTS}

The authors thank the Direction of access to health products, Direction of medical biology labs and all the vegetable sellers of the Wayalghin and Tanghin markets for their assistance and contribution to this study.

\section{REFERENCES}

Akiba M, Senba H, Otagiri H, Prabhasankar VP, Taniyasu S, Yamashita N, Lee K, Yamamoto $\mathrm{T}$, Tsutsui $\mathrm{T}$, Ian $\mathrm{D}$, Balakrishna K, Bairy I, Iwata T, Kusumoto M, Kannan K, Guruge KS. 2015. Impact of wastewater from different sources on the prevalence of antimicrobial-resistant Escherichia Coli in sewage treatment plants in South India. Ecotoxicol. Environ. Saf ., 115: 203-208. 
DOI:

https://doi.org/10.1016/j.ecoenv.2015.02. 018.

Blaak H, Hoek AHAMV, Veenman C, Leeuwen AEDV, Lynch G, Overbeek WMV, Maria A, Husman DR. 2014. Extended spectrum $\beta$-Lactamase- and constitutively AmpC-producing Enterobacteriaceae on fresh produce and in the agricultural environment. Int. J. Food Microbiol., 168-169: 8-16. DOI: https://doi.org/10.1016/j.ijfoodmicro.201 3.10.006.

CA-SFM. 2013. Antibiogramm Committee of French Society for Microbiology. CASFM, Version 5. Available at www.sfmmicrobiologie.org

Baylis C, Uyttendaele M, Joosten H, Davies A. 2011. The Enterobacteriaceae and Their Significance to the Food Industry. ILSI Europ: Belgium.

Doi Y, Iovleva A, Bonomo RA. 2017. The ecology of extended-spectrum $\beta$ Lactamases ( ESBLs ) in the developed world. J. Travel Med., 24(1): 44-51. DOI: https://doi.org/10.1093/jtm/taw102.

Drechsel P, Graefe S, Sonou M, Cofie OO. 2006. Informal Irrigation in Urban West Africa: An Overview. Research Report 102, International Water Management Institute, Colombo-Sri Lanka.

Gundran RS, Cardenio PA, Salvador RT, Sison FB, Benigno CC, Kreausukon K, Pichpol D, Punyapornwithaya V. 2020. Prevalence, antibiogram, and resistance profile of extended-spectrum $\beta$ lactamase-producing Escherichia Coli isolates from pig farms in Luzon, Philippines. Microb. Drug Resist., 26(2): 160-168.

DOI: https://doi.org/10.1089/mdr.2019.0019.

Kêdowidé CMG, Sedogo MP, Cisse G. 2010. Dynamique spatio temporelle de l'agriculture urbaine à Ouagadougou : cas du maraîchage comme une activité montante de stratégie de survie. VertigO, 10(2) : 1-22. DOI: https://doi.org/id.erudit.org/iderudit/0455 10ar.

Kpoda DS, Guessennd N, Bonkoungou JI,
Ouattara B, Konan F, Ajayi A, Simpore J, Drabo KM, Sangare L, Dosso M, Traore A. 2017. Prevalence and resistance rrofile of extended-Spectrum $\beta$-lactamasesproducing Enterobacteriaceae in Ouagadougou, Burkina Faso. Afr. J. Microbiol. Res.,11(27): 1120-26. DOI: https://doi.org/10.5897/AJMR2017.8598

Lan SM, Amaeze NH, Obanya HE, Okoroafor CU. 2019. Occurrence of selected pharmaceuticals in industrial wastewater , receiving waters and fish. Afr. J. Aquat. Sci., 44(4): 401-408. DOI: https://doi.org/10.2989/16085914.2019.1 680339

Lauderdale TY, Wang J, Lee W. 2010. "Carriage rates of methicillin-resistant Staphylococcus Aureus ( MRSA) depend on anatomic location, the number of sites cultured, culture methods, and the distribution of clonotypes." Eur. J. Clin. Microbiol. Infect. Dis., 29: 1553-1559. DOI: https://doi.org/10.1007/s10096010-1042-8

Maestre-carballa L, Gomez ML, Navarro AA, Garcia-heredia I, Martinez-hernandez F, Martinez-garcia M. 2019. Insights into the antibiotic resistance dissemination in a wastewater effluent microbiome: bacteria, viruses and vesicles matter. Environ. Microbiol., 21(12): 4582-96. DOI: $\quad$ https://doi.org/10.1111/14622920.14758.

Maravić A, Skočibušić M, Cvjetan S, Šamanić I, Fredotović Ž, Puizina J. 2015. Prevalence and diversity of extendedspectrum- $\beta$-lactamase-producing

Enterobacteriaceae from marine beach waters. Mar. Pollut. Bull., 90(1-2): 60-67. DOI:

https://doi.org/10.1016/j.marpolbul.2014 .11 .021

Ndir A, Diop A, Ka R, Faye PM, Dia-badiane NM, Ndoye B, Astagneau P. 2016. Infections caused by extended-spectrum $\beta$-lactamases

Enterobacteriaceae : clinical and economic impact in patients hospitalized in 2 teaching hospitals in Dakar, Senegal. Antimicrob. Resist. Infect. Control., 
5(13): $\quad 1-8 . \quad$ DOI: https://doi.org/10.1186/s13756-0160114-7.

Osinka A, Korzeniewska E, Harnisz M, Niestepski S. 2016. The prevalence and characterization of antibiotic-resistant and virulent Escherichia coli strains in the municipal wastewater system and their environmental fate. Sci. Total Environ., 577(1): 364-375. DOI: https://doi.org/10.1016/j.scitotenv.2016. 10.203 .

Ouédraogo AS, Jean Pierre H, Banul AL, Ouédraogo R, Godreuil S. 2017. Emergence and spread of antibiotic resistance in West Africa: contributing factors and threat assessment. Med. Sante Trop., 27: 147-54. DOI: https://doi.org/10.1684/mst.2017.0678.

Ouédraogo AS, Sanou S, Kissou A, Poda A, Aberkane S, Bouzinbi N, Nacro B, Ouédraogo R, Perre PVD, Carriere C, Decré D, Jean-Pierre H, Godreuil S. 2017. Fecal carriage of Enterobacteriaceae producing extended-spectrum $\beta$ Lactamases in hospitalized patients and healthy community volunteers in Burkina Faso. Microb. Drug Resist., 23(1): 63-70. DOI: https://doi.org/10.1089/mdr.2015.0356.

Ouedraogo AS, Sanou M, Kissou A, Sanou S, Solaré H, Kaboré F, Poda A, Aberkane S, Bouzinbi N, Sano I, Nacro B, Sangaré L, Carrière C, Decré D, Ouégraogo R, Jeanpierre H. 2016. High prevalence of extended-spectrum B-lactamase producing Enterobacteriaceae among clinical isolates in Burkina Faso. BMC Infect. Di., 16: 1-9. DOI: https://doi.org/10.1186/s12879-0161655-3.

Ouedraogo DB, Gnankambary Z, Bismarck H, Papaoba M. 2018. Characterization and use of wastewater in horticulture in Ouagadougou, Burkina Faso. Int. J. Biol. Chem. Sci., 12(6): 2564-77. DOI: https://doi.org/https://dx.doi.org/10.4314 /ijbcs.v12i6.8.

Priyanka U, Nandan A. 2014. Bacterial dynamics in antibiotic wastewater treatment - a review. Int. J. OHSFEAllied Sci., 2(1): 001-008.

Richter L, Du Plessis EM, Duvenage S, Korsten L. 2019. Occurrence, identification, and antimicrobial resistance profiles of extended-spectrum and AmpC $\beta$-lactamase-producing Enterobacteriaceae from fresh vegetables retailed in Gauteng Province, South Africa. Foodborne Pathog. Dis., 16(6): 421-27.

DOI:

https://doi.org/10.1089/fpd.2018.2558.

Rousham EK, Unicomb L, Islam MA. 2018. Human , animal and environmental contributors to antibiotic resistance in low-resource settings: integrating behavioural, epidemiological and one health approaches. Proc. R. Soc., B., 285: 1-9.

DOI: https://doi.org/10.1098/rspb.2018.0332.

Sallem RB, Slama KB, Saenz Y, Rojo-bezares B, Estepa V, Jouini A, Haythem G, Klibi N, Boudabous A, Torres C. 2012. Prevalence and characterization of extended-spectrum $\quad \beta$-Lactamase (ESBL)- and CMY-2-producing Escherichia coli isolates from healthy food-producing animals in Tunisia. Foodborne Pathog. Dis., 9(12): 11371142.

DOI: https://doi.org/10.1089/fpd.2012.1267.

Samandoulougou S, Ilboudo AJ, Bagre TS, Tapsoba FW, Savadogo A, Scippo M, Traore AS. 2015. Screening of antibiotics residues in beef consumed in Ouagadougou, Burkina Faso. Afr. J. Food Sci., 9(6): 367-71. DOI: https://doi.org/10.5897/AJFS2015.1291

Sanou S, Ouedraogo AS, Lounnas M, Zougmore A, Poda A, Zoungrana J, Ouedraogo GA, Traore/Ouedraogo R, Ouchar O, Carriere C, Pierre HJ, Godreuil S. 2019. Epidemiology and molecular characterization of Enterobacteriaceae producing extended spectrum $\beta$ lactamase in extensive and extensive breeding animals in Burkina Faso. Research Square, 4(1): 1-16. DOI: https://doi.org/10.21203/rs.2.9603/v1 
Sou M. 2009. Recyclage des eaux usées en irrigation: potentiel fertilisant, risques sanitaires et impacts sur la qualité des sols. Ecole polytechnique fédérale de Lausanne, Lausanne.

Svobodova K, Semerad J, Petrackova D, Novotny C. 2018. Antibiotic resistance in Czech urban wastewater treatment Plants. Microb. Drug Resist., 24(6): 830-838. DOI:

https://doi.org/10.1089/mdr.2017.0406.

Tao R, Ying G, Su H, Zhou H, Sidhu JPS. 2010. Detection of antibiotic resistance and tetracycline resistance genes in Enterobacteriaceae isolated from the Pearl Rivers in South China. Environ. Pollut., 158(6): 2101-2109. DOI: https://doi.org/10.1016/j.envpol.2010.03. 004.

Thevenon F, Adatte T, Wildi W, Poté J. 2012. Antibiotic resistant bacteria / genes dissemination in lacustrine sediments highly increased following cultural eutrophication of lake Geneva (Switzerland). Chemosphere, 86(5): 468-
76.

DOI:

https://doi.org/10.1016/j.chemosphere.20 11.09.048.

WHO. 2014. Antimicrobial resistance : global report on surveillance. WHO.

Ye Q, Wu Q, Zhang S, Zhang J, Yang G, Wang $\mathrm{H}$, Huang J, Chen M, Xue L, Wang J. 2017. Antibiotic-Resistant Extended Spectrum B-Lactamase- and Enterobacteriaceae isolated from retail food products and the Pearl River in Guangzhou, China. Front. Microbiol., 8(96): $1-12$. DOI: https://doi.org/10.3389/fmicb.2017.0009 6.

Zurfluh K, Nüesch-Inderbinen M, Morach M, Zihler Berner A, Hächler H, StephanR. 2015. Extended-spectrum $\beta$-lactamaseproducing Enterobacteriaceae isolated from vegetables imported from the Dominican Republic, India, Thailand, and Vietnam. Appl. Environ. Microbiol., 81(9): $\quad 3115-3120 . \quad$ DOI: https://doi.org/10.1128/AEM.00258-15. 